\title{
Hypothalamic Alterations in Obesity
}

\author{
Simone van de Sande-Lee ${ }^{* 1,2}$ and Licio A Velloso ${ }^{2}$
}

${ }^{1}$ Departamento de Clínica Médica, Centro de Ciências da Saúde, Universidade Federal de Santa Catarina, Florianópolis, Santa Catarina, Brazil

${ }^{2}$ Laboratory of Cell Signaling, Obesity and Comorbidities Research Centre, University of Campinas, Campinas, São Paulo, Brazil

*Corresponding author: Simone van de Sande-Lee, Universidade Federal de Santa Catarina, Hospital Universitário, Departamento de Clínica Médica, Campus Universitário-Trindade, 88040-970, Florianópolis, SC, Brazil, Tel: +55 48 37219014; Fax: +55 48 37219149; E-mail: simonevslee@yahoo.com.br

Received date: December 30, 2014; Accepted date: March 20, 2014; Published date: March 24, 2014

Copyright: @2014 van de Sande-Lee S and Velloso LA. This is an open-access article distributed under the terms of the Creative Commons Attribution License, which permits unrestricted use, distribution, and reproduction in any medium, provided the original author and source are credited.

\begin{abstract}
Obesity is a major public health problem. Excess adiposity reflects an imbalance between food intake and energy expenditure, resulting from complex interactions between genetic and environmental factors. In animals and humans, the control of energy homeostasis is performed by the Central Nervous System (CNS) through neuroendocrine connections, in which circulating peripheral hormones such as leptin and insulin provide a signal to specialized neurons of the hypothalamus reflecting body fat stores, and inducing appropriate responses to maintain the stability of these stores. Obesity is commonly associated with central resistance to both leptin and insulin actions. In experimental animals, high-fat diets can induce an inflammatory process in the hypothalamus, which impairs leptin and insulin intracellular signaling pathways and results in hyperphagia, decreased energy expenditure and ultimately obesity. Recent evidence, obtained from neuroimaging studies and analysis of inflammatory markers in the cerebrospinal fluid of obese subjects, suggest that similar alterations may be also found in humans. In this review, we briefly present the mechanisms involved with deterioration of homeostatic control of energy balance in animal models of obesity and the current evidence of hypothalamic dysfunction in obese humans.
\end{abstract}

Keywords: Obesity; Central nervous system; Hypothalamus

\section{Abbreviations}

AKT: Protein Kinase B; CNS: Central Nervous System; CSF: Cerebrospinal Fluid; ERS: Endoplasmic Reticulum Stress; fMRI: Functional Magnetic Resonance Imaging; GLP-1: Glucagon-Like

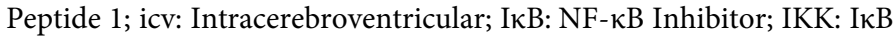
Kinase; IL: Interleukin; IR: Insulin Receptor; IRS: Insulin Receptor Substrate; JAK2: Janus Kinase-2; JNK: c-Jun N-terminal Kinase; LepR: Leptin Receptor; LepR-1: Long Isoform of Leptin Receptor; NFkB: Nuclear Factor Kappa B; ObR: Leptin Receptor; ObRb: Long Isoform of Leptin Receptor; PDK: Phosphoinositide-Dependent Kinase; PET: Positron Emission Tomography; PI3K: Phosphatidylinositol-3-kinase; PIP2: Phosphatidylinositol Bisphosphate; PIP3: Phosphatidylinositol Triphosphate; PKC- $\theta$ : Protein Kinase C- $\theta$; POMC: Proopiomelanocortin; PTP1B: Protein Tyrosine Phosphatase-1B; SOCS-3: Suppressor of Cytokine Signaling-3; STAT3: Signal Transducer and Activator of Transcription 3; TLR-4: Toll-Like Receptor 4; TNF- $\alpha$ : Tumor Necrosis Factor- $\alpha$; UPR: Unfolded Protein Response; VMH: Ventromedial Hypothalamus

\section{Introduction}

Obesity is currently one of the major public health problems in the world. According to the World Health Organization, over 1.4 billion adults were overweight in 2008 and of these, nearly 200 million men and 300 million women were obese [1]. Compared to data from 1980, obesity prevalence almost doubled [1], and if trends continue, up to 3.3 billion people could be either overweight or obese by 2030 [2]. In addition to imposing a social stigma on individuals, obesity is a risk factor for several disorders, such as type 2 diabetes mellitus, hypertension, dyslipidemia, respiratory diseases, osteoarthritis, cardiovascular events and cancer, impacting on life quality and mortality $[3,4]$.

Family studies, comprising analysis of twins and adopted children, have demonstrated a significant contribution of hereditary traits on body mass [5]. However, only a small fraction of severe obesity cases involve mutations in a single gene. For the vast majority of the population, variation in adiposity results from complex interactions between a large number of genetic variants and environmental factors [5]. Contemporary lifestyle is pointed as the main responsible for the rapid rise in obesity prevalence [3]. If energy efficiency has favored survival in periods of scarcity, nowadays we face the opposite situation. Since the industrial revolution, the lifestyle of much of the world's population has undergone profound shifts. Advances in hygiene, science and public health, in addition to increased job offers and food availability allowed a significant rise in life expectancy [6]. On the other hand, the lower cost of highly palatable, calorie dense foods, coupled with the lesser requirement of physical activity in daily life, led to an alarming increase in the prevalence of obesity, threatening to counteract the gains achieved [7].

Body fat accumulation is invariably caused by an imbalance between food intake and energy expenditure, a problem that has a seemingly simple solution. Nevertheless, to date no action has been effective in reversing or even containing the progress of this problem. Despite the common thought that eating is a voluntary act, recent evidence indicates that the balance between energy intake and expenditure is actually controlled by a complex and powerful biological system, driven by the CNS [8]. Flaws in this system may lead to the emergence and aggravation of obesity. 


\section{The Role of the Hypothalamus in Energy Homeostasis- Historical Background}

Body energy balance is controlled by specific populations of neurons located, mostly, in the hypothalamus [8]. Early indications emerged in 1840, from the description of a woman who had become extremely obese within the year preceding her death, and whose autopsy revealed a large pituitary tumor compressing the base of the brain [9]. Similar cases were reported until the early twentieth century, when Fröhlich hypothesized that the pituitary lesion would be the cause of obesity. This hypothesis was challenged a few years later by Erdheim, who noticed that in some cases no significant damage was found in the pituitary gland, while compression of the base of the brain was invariably present [9]. The matter remained controversial until the late 30s and early 40s, when Hetherington and Ranson first demonstrated the development of marked hyperphagia and obesity in rats submitted to lesions of the Ventromedial Hypothalamus (VMH) by an electrode introduced from above, leaving the pituitary intact [10]. Later, Anand and Brobeck described the development of aphagia in rats and cats after bilateral lesion of a small area located in the lateral hypothalamus [11]. Based on these studies, the lateral hypothalamus was designated as the "feeding center" and the ventromedial hypothalamus, as the "satiety center" [12].

Under normal conditions, an adult animal's fat mass remains stable over long periods, despite fluctuations in food intake and physical activity. Food-restricted animals return to their initial weight as soon as the supply is reestablished [13], and manipulation of food energy density through its dilution in inert material results in suitability of the ingestion to the amount of calories, not to the volume [14]. In order to couple calorie consumption with expenditure and keep energy stores constant, the brain should be able to obtain information about the amount of these stores. In 1953, Kennedy proposed that the hypothalamus could detect the concentration of circulating metabolites [15]. This hypothesis was strengthened by data obtained from parabiosis experiments, in which the blood vessels of two animals are surgically joined to allow the exchange of humoral factors [16]. When a lean rat was parabiosed to a rat with obesity caused by a $\mathrm{VMH}$ lesion, the first presented hypophagia and weight loss, suggesting that an obesity-related signal is able to inhibit food intake, and hypothalamic integrity is required to its action [16]. One more step has been taken after the description of two mouse models of obesity, originated from spontaneous monogenic mutation with an autosomal recessive inheritance pattern, the ob/ob [17] and $\mathrm{db} / \mathrm{db}$ mice [18]. Both present extreme obesity as a consequence of hyperphagia and decreased energy expenditure. The parabiosis of $\mathrm{ob} / \mathrm{ob}$ to lean mice resulted in weight loss only in obese animals, whereas when the same experiment was repeated with $\mathrm{db} / \mathrm{db}$ mice, weight loss was observe only in lean controls [19]. The conclusion was that ob/ob animals lack a circulating factor that inhibits food intake, while $\mathrm{db} / \mathrm{db}$ mice produce this factor in excess, but are not able to respond to it. After these results, it became clear that fat mass is controlled by neuroendocrine connections. However, some more years were required until the development of positional cloning technique allowed identification of leptin by cloning the ob gene [20] and leptin receptor by cloning the $\mathrm{db}$ gene [21].

\section{Leptin, the Main Adiposity Signal}

Leptin (from the Greek word for thin, leptos) is a polypeptide produced by white adipose tissue and secreted into the circulation in direct proportion to its mass $[20,22,23]$. Leptin crosses the blood-brain barrier and binds to its receptor (ObR or LEPR), which belongs to a cytokine family receptor [21]. Although it is found broadly, the long isoform (ObRb or LEPR-1), the one that has all the protein domains required for signaling, is expressed mainly in the hypothalamus [23]. It is noteworthy that only this isoform is mutant in $\mathrm{C} 57 \mathrm{BL} / \mathrm{Ks} \mathrm{db} / \mathrm{db}$ mice, whose phenotype is identical to that of animals with complete deletions of ob or ObRb gene [24]. ObRb is constitutively bound to a cytosolic protein with tyrosine kinase activity, called JAK2 (Janus kinase-2) [25]. Leptin binding promotes receptor dimerization with tyrosine phosphorylation of JAK2, which in turn catalyzes the phosphorylation of tyrosine residues in the intracellular portion of the receptor. A number of proteins involved in signal transduction are activated, including STAT3 (signal transducer and activator of transcription 3), which is translocated to the nucleus and regulates gene expression of neurotransmitters and other proteins (Figure 1) [26]. Simultaneously, the activation of JAK and STAT induces the expression of signaling inhibitors such as SOCS-3 (suppressor of cytokine signaling 3) and PTP1B (protein tyrosine phosphatase-1B) negatively modulating the biological response to leptin $[27,28]$.

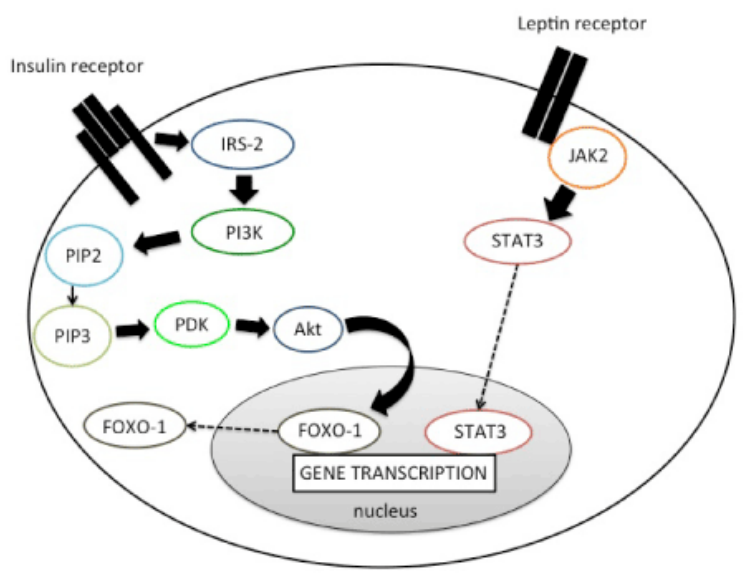

Figure 1: Leptin and insulin signaling pathways.

Peripheral administration of leptin decreases food intake and leads to weight loss in ob/ob mice and, to a lesser extent, in lean controls, but has no effect in db/db mice [29-31]. Similar results are observed after intracerebroventricular (icv) administration of small doses, insufficient to modify leptin peripheral concentration, indicating that these effects arise from central actions [31]. These data confirmed the existence of a homeostatic system, in which leptin, through a negative feedback loop, modulates the activity of neuronal circuits that control adipose tissue mass.

After leptin identification, the knowledge about physiologic processes that regulate energy balance rapidly increased. Several other circulating factors, mainly produced by adipose tissue, gastrointestinal tract and pancreas, in addition to the nutrients themselves, may influence feeding behavior by acting on the hypothalamus and other areas of the CNS [32]. For example, cholecystokinin, glucagon-like peptide-1 (GLP-1) and peptide YY are hormones produced by specialized enteroendocrine cells in the gastrointestinal tract, phasically secreted in response to feeding [33]. Although these peptides may influence meal size, acting as satiety signals, their action on adipose tissue mass is not as relevant. For this to happen, the factor 
must be tonically active and proportional to the amount of fat stored such as leptin, considered the main adiposity signal in the body. Besides leptin, another hormone is able to play this role: insulin [34].

\section{Insulin and Energy Homeostasis}

Although recent data indicate that insulin plays a secondary role as an adiposity negative-feedback signal, it was the first hormone to be studied in this regard. Several experiments with different species have been conducted over the last four decades, demonstrating that icv administration of insulin decreases food intake and increases energy expenditure [34]. Insulin is produced by pancreatic beta cells and is tonically secreted with increases during meals. Both basal and stimulated components of the secretion are directly proportional to adiposity [35]. As leptin, insulin crosses the blood-brain barrier and acts on receptors predominantly expressed in hypothalamic neurons. After insulin binding to the extracellular a subunit of its receptor (IR), the intracellular $\beta$ subunit autophosphorylates, promoting the recruitment and tyrosine phosphorylation of insulin receptor substrate (IRS) [36]. Among members of IRS protein family, IRS-2 is the one with highest expression in the hypothalamus and is the main responsible for mediating the central effects of insulin. Phosphorylated IRS-2 binds to the regulatory subunit (p85) of the phosphatidylinositol-3-kinase enzyme (PI3K), activating its catalytic subunit (p110), which in turn phosphorylates phosphatidylinositol bisphosphate (PIP2) to produce phosphatidylinositol triphosphate (PIP3). PIP3 is a key signaling molecule that recruits and activates other intermediate proteins of insulin-signaling pathway, such as PDK and Akt. Phosphorylated Akt, among other downstream signaling events, inactivates FOXO-1 mediated transcription by promoting its nuclear exclusion (Figure 1) $[37,38]$. Insulin central actions on energy balance are similar to those of leptin, that is, in contrast to the anabolic effects on peripheral tissues, insulin hypothalamic actions produce catabolic effects [39]. There is apparently a cross-talking between the signaling pathways of leptin and insulin in the CNS, by which leptin actions are positively modulated by insulin and vice versa [40].

\section{Hypothalamic Resistance to Leptin and Insulin}

Soon after the identification of leptin, researchers realized that the vast majority of obese subjects did not lack leptin or insulin. Circulating levels of these hormones were rather increased [22], and yet there was no reduction in food intake. Thus, they postulated that common forms of obesity were associated with resistance to the central actions of adiposity signals [41]. Indeed, leptin treatment was relatively ineffective in most of those cases $[42,43]$, and the response to central administration of leptin and insulin is attenuated in animal models of diet-induced obesity [44,45]. In recent years, several experimental studies have contributed to advances in knowledge about the mechanisms involved in hypothalamic resistance to these hormones. The main findings revealed the induction of an inflammatory process specifically in the hypothalamus, which activates intracellular signaling pathways that attenuate leptin and insulin biological effects [40,44-47].

The most important mechanisms leading to leptin and insulin resistance are apparently associated to postreceptor defects [40,44-47]. Peripheral insulin resistance induced by obesity-associated low-grade chronic inflammation had been known for some time [48-50]. Hotamisligil et al. demonstrated that the induction of tumor necrosis factor- $\alpha$ (TNF- $\alpha$ ) mRNA expression in adipose tissue of animal models of obesity and diabetes [48]. Furthermore, there was a rise in local and systemic levels of the protein, and its neutralization significantly increased peripheral glucose uptake in response to insulin [48]. However, only in 2005 such a phenomenon was described in the hypothalamus [46]. De Souza et al. studied the effect of diet on gene expression patterns in the hypothalamus of rats, and reported a significant rise in inflammatory proteins expression, such as TNF- $\alpha$, pro-interleukin-1 $\beta$ (IL-1 $\beta$ ) and interleukin-6 (IL-6) after 16 weeks of high-fat diet [46], accompanied by activation of protein kinases such as c-Jun N-teminal kinase (JNK) and IKB kinase (IKK) $[46,51,52]$. Activated JNK catalyzes the serine phosphorylation of IRS, which reduces the activation of PI3K/Akt [46]. Genetic or pharmacological inhibition of JNK in the hypothalamus of rodents restores insulin signaling [46,51]. IKK is expressed in neurons of the mediobasal hypothalamus, but normally remains inactive. When activated, it phosphorylates $\mathrm{I} \kappa \mathrm{B}$, a protein that sequesters NF- $\kappa \mathrm{B}$ (nuclear factor$\kappa \mathrm{B}$ ) in the cytoplasm. The phosphorylated $\mathrm{I} \kappa \mathrm{B}$ is degraded, releasing $\mathrm{NF}-\kappa \mathrm{B}$ to translocate to the nucleus and mediate transcription of inflammatory genes [52]. The activation of this pathway in mice leads to insulin and leptin resistance in the hypothalamus, hyperphagia and weight gain, while its deletion protects against the development of obesity [52]. Hypothalamic inflammation may also impair leptin and insulin signaling by inducing physiological inhibitors of these pathways, such as SOCS3 [27,53-55] and PTP1B [28,56,57]. Besides stimulation by leptin itself, SOCS expression may also be induced by several cytokines and lipopolysaccharides [54]. SOCS3 can directly inhibit or facilitate degradation of receptors and signaling proteins [54], and its expression is increased in the hypothalamus of high-fat fed mice [58]. While neuron-specific deletion of SOCS3 protects against diet-induced obesity [53], overexpression of SOCS3 in POMC neurons induces leptin resistance, obesity and impaired glucose tolerance [55]. The proinflammatory cytokine TNF- $\alpha$ may induce expression of PTP1B, via NF- $\kappa B$ activation [59]. PTP1B inhibits insulin and leptin signaling by dephosphorylating the insulin receptor, JAK2 and other signaling molecules [28]. Hypothalamic PTP1B expression increases in response to high-fat diet and to TNF- $\alpha$ systemic administration [59], and inhibition of PTP1B in CNS of rodents leads to reduced adiposity and enhanced leptin and insulin sensitivity [56,57]. In addition, PKC- $\theta$ (protein kinase C- $\theta$ ) can mediate the deleterious effects of high-fat diet on central adipostatic signaling [60]. Central exposure to palmitic acid induces activation of PKC $-\theta$, which reduces insulin signaling. PKC $-\theta$ knockdown in the hypothalamus improves local insulin signaling and peripheral glucose homeostasis, besides reducing diet-induced weight gain [60].

The data presented above show that manipulating the various mechanisms involved in hypothalamic leptin and insulin resistance may modify adiposity, which suggests that these alterations are not just an extension of the inflammation found in the periphery, but are engaged in obesity pathogenesis, at least in animal models [8]. In support of this hypothesis, diet-induced hypothalamic inflammation precedes weight gain and adipose tissue inflammation in rodents $[45,61]$.

Among the potential mechanisms involved in the connection between fatty acids and hypothalamic inflammation are the activation of Toll-like receptor 4 (TLR4) and the endoplasmic reticulum stress (ERS) [62-65]. TLR4 is a cell surface receptor of the innate immune system that recognizes lipopolysaccharides of the Gram-negative bacteria cell wall. Within the CNS, it is expressed predominantly in microglia cells [66]. Central injection of long chain saturated fatty acids, but not monounsaturated fatty acids, induces a local inflammatory response by activating TLR4 [62]. The deletion of either 
TLR4 or MyD88-an essential adapter protein in the induction of proinflammatory cytokines by TLR4-protects against the development of leptin and insulin resistance and diet-induced obesity $[62,63]$. Nutrient excess, particularly saturated fatty acids, can also trigger ERS, which in turn activates inflammatory pathways [62,64]. The endoplasmic reticulum is responsible for the synthesis and maturation of a number of proteins. Improper folding of newly formed proteins may have deleterious consequences for the cell and leads to the initiation of an adaptive response called UPR (unfolded protein response) during which global translation is reduced, as part of a biological strategy that aims solving the process [64]. ERS seems to play a key role in the induction of hypothalamic leptin resistance. Its inhibition restores leptin sensitivity and reduces weight in mice fed a high-fat diet, while its induction in neurons leads to leptin resistance and obesity [65]. The mechanisms by which ERS is induced in the presence of high-fat diet are not well understood. It has been suggested that lipids could directly affect the homeostasis of the endoplasmic reticulum, by changing membrane composition and depleting calcium stores $[67,68]$. However, a study from our group demonstrated that TLR4 inhibition is sufficient to improve ERS upon high-fat feeding or icv injection of saturated fatty acids, suggesting that it is secondary to TLR4 activation [62].

It has recently been shown that a hyperlipidic diet may also be associated with apoptosis of hypothalamic neurons in rodents [69]. Interestingly, the activation of apoptotic proteins is more closely related to the diet composition than to the amount of calories consumed or body mass [69]. Another level of regulation that may be important in energy homeostasis control is synaptic plasticity. Diet and peripheral metabolic hormones can influence the organization of synaptic connections between hypothalamic neurons [70-72]. Changes in these connections together with neuronal apoptosis might be related to the difficulty in completely reversing excessive adiposity, even with cessation of the stimulus that initiated the hypothalamic inflammation [8]. On the other hand, neurogenesis has also been described in the adult rodent hypothalamus, and modulation of this process may potentially re-establish energy balance [73].

\section{Hypothalamic Alterations in Obese Humans}

Despite recent advances in characterizing hypothalamic alterations in animal models of obesity, there is no evidence to date that the same molecular mechanisms may contribute to the development of obesity in humans [8]. It is well known that the presence of leptin and the integrity of its signaling pathways are crucial to energy homeostasis also in humans, since null mutations in genes encoding leptin, leptin receptor, or downstream neurotransmitters or receptors cause hyperphagia and severe obesity that, in the case of leptin deficiency, are reversed following treatment with human recombinant leptin [74,75]. Most obese individuals show hyperleptinemia, and leptin treatment in these cases is relatively ineffective, indicating leptin resistance $[22,42,43]$. However, due to technical difficulties in studying human CNS, the underlying mechanisms remain obscure.

Since it is not possible to directly evaluate human brain tissue in vivo, one way of investigating CNS biomarkers is through the analysis of cerebrospinal fluid (CSF), which is in direct contact with neuronal tissue. Stenlöf et al. [76] demonstrated that the levels of IL-6 in CSF of overweight or obese subjects is negatively correlated with body fat. More recently, a study by our group showed that IL- 6 levels in the CSF of severely obese subjects are significantly lower compared to lean ones, and increase after bariatric surgery-induced weight loss [77].
Conversely, peripheral levels of IL-6 are increased in obesity $[77,78]$. IL-6 is a pleiotropic cytokine that may exert either pro- or antiinflammatory actions, depending on concentration, target tissue and probably species [78]. In adipocytes, IL-6 induces insulin resistance and its expression is increased in cells of insulin resistant subjects [79]. In mice, both acute and chronic peripheral administration of IL-6 impaired insulin sensitivity in the liver, and IL-6 neutralization improved hepatic insulin resistance [80-82]. On the other hand, whole-body IL- 6 gene deletion in mice led to obesity and impaired glucose tolerance in adulthood, which was partially reversed by replacement of IL-6 at low doses [83]. Mice overexpressing human IL- 6 in the brain and lungs exhibited enhanced insulin and leptin sensitivity [84]. In addition, acute icv-but not peripheral-injection of IL-6 in rats increased energy expenditure, suggesting that the antiobesity effects of IL- 6 are exerted mainly through its actions on the CNS [83]. A recent study has shown that central injection of a GLP1 receptor agonist with well-known weight-lowering effects potently increased hypothalamic expression of IL-6 [85]. IL-6 can also be produced and released by skeletal muscle, and mediate the effects of exercise on metabolism [86]. Physical activity-induced improvement in leptin and insulin sensitivity in the hypothalamus of rats seems to be dependent on IL-6 central actions [87], a mechanism that also involves induction of IL-10 [88]. IL-10 is a classical anti-inflammatory cytokine which curbs neuronal degeneration through inhibition of apoptosis [89]. We have observed, in obese patients undergoing bariatric surgery, a significant increase in CSF levels of IL-10 after weight loss [77], pointing towards an anti-inflammatory effect. Regarding IL-6, evidence is still limited, and the effects of this cytokine on systemic metabolism seem to be considerably complex. Although some data suggest that IL- 6 actions in CNS can positively affect insulin and leptin sensitivity, we have previously shown that its expression is increased in the rat hypothalamus after a high-fat diet [46]. Thus, additional work is necessary to further understand the role of IL- 6 as a biomarker of hypothalamic inflammation.

Another way of evaluating human CNS is by neuroimaging studies. Techniques such as functional magnetic resonance imaging (fMRI) and positron emission tomography (PET) allow noninvasive detection of dynamic functional changes of CNS regions associated with cognitive and behavioral processes [90-92]. Neuroimaging studies have demonstrated significant differences in hypothalamic activity in response to food intake between obese and lean subjects [93-95]. We have recently evaluated reversibility of these changes after bariatric surgery-induced weight loss. Obese subjects, when compared to lean controls, showed distinct patterns of brain activity in response to glucose ingestion, which are partially reversed following body mass reduction [77]. We don't know whether a greater weight loss or a longer period of time elapsed from the surgery would completely restore the dysfunction. Should the neuronal apoptosis phenomenon as described in obese rodents also occur in humans, complete reversal might not be achieved. Accordingly Thaler et al. found evidence of increased gliosis in the mediobasal hypothalamus of obese humans using structural magnetic resonance imaging. These findings suggest that, as observed in experimental animals, obesity in humans is associated with neuronal injury in the hypothalamus [61].

\section{Conclusion}

The understanding of the mechanisms contributing to the deterioration of the homeostatic control of energy balance in animal models of obesity has grown considerably in recent years. These 
Page 5 of 7

mechanisms involve the development of an inflammatory process in the hypothalamus and eventually neuronal damage, resulting in local resistance to leptin and insulin. In humans there is also evidence, albeit indirect, that similar alterations are present in obesity. Interventions to halt or limit this process might become important strategies for the prevention and treatment of obesity and related diseases.

\section{Acknowledgments}

The authors' research is supported by Fundação de Amparo à Pesquisa do Estado de São Paulo (Brazil).

\section{References}

1. WHO. Obesity and overweight (n.d.).

2. Kelly T, Yang W, Chen CS, Reynolds K, He J (2008) Global burden of obesity in 2005 and projections to 2030. Int J Obes (Lond) 32: 1431-1437.

3. Kopelman PG (2000) Obesity as a medical problem. Nature 404: 635-643.

4. Kramer CK, Zinman B, Retnakaran R (2013) Are metabolically healthy overweight and obesity benign conditions?: A systematic review and meta-analysis. Ann Intern Med 159: 758-769.

5. Farooqi S, O'Rahilly S (2006) Genetics of obesity in humans. Endocr Rev 27: 710-718.

6. Haslam D (2007) Obesity: a medical history. Obes Rev 8 Suppl 1: 31-36.

7. Swinburn BA, Sacks G, Hall KD, McPherson K, Finegood DT, et al. (2011) The global obesity pandemic: shaped by global drivers and local environments. Lancet 378: 804-814.

8. Velloso LA, Schwartz MW (2011) Altered hypothalamic function in dietinduced obesity. Int J Obes (Lond) 35: 1455-1465.

9. Brobeck JR, Tepperman J, Long CN (1943) Experimental Hypothalamic Hyperphagia in the Albino Rat. Yale J Biol Med 15: 831-853.

10. Hetherington AW, Ranson SW (1939) Experimental HypothalamicoHypophyseal Obesity in the Rat. Proc Soc Exp Biol Med 41: 465 -466.

11. Anand BK, Brobeck JR (1951) Hypothalamic control of food intake in rats and cats. Yale J Biol Med 24: 123-140.

12. Arees EA, Mayer J (1967) Anatomical connections between medial and lateral regions of the hypothalamus concerned with food intake. Science 157: 1574-1575.

13. Liebelt RA, Vismara L, Liebelt AG (1968) Autoregulation of adipose tissue mass in the mouse. Proc Soc Exp Biol Med 127: 458-462.

14. Adolph EF (1947) Urges to eat and drink in rats. Am J Physiol 151: 110-125.

15. Kennedy GC (1953) The role of depot fat in the hypothalamic control of food intake in the rat. Proc R Soc Lond B Biol Sci 140: 578-596.

16. Hervey GR (1959) The effects of lesions in the hypothalamus in parabiotic rats. J Physiol 145: 336-352.

17. Ingalls AM, Dickie MM, Snell GD (1950) Obese, a new mutation in the house mouse. J Hered 41: 317-318.

18. Hummel KP, Dickie MM, Coleman DL (1966) Diabetes, a new mutation in the mouse. Science 153: 1127-1128.

19. Coleman DL (1973) Effects of parabiosis of obese with diabetes and normal mice. Diabetologia 9: 294-298.

20. Zhang Y, Proenca R, Maffei M, Barone M, Leopold L, et al. (1994) Positional cloning of the mouse obese gene and its human homologue. Nature 372: 425-432.

21. Tartaglia LA, Dembski M, Weng X, Deng N, Culpepper J, et al. (1995) Identification and expression cloning of a leptin receptor, OB-R. Cell 83: 1263-1271.

22. Considine R, Sinha MK, Heiman ML, Kriauciunas A, Stephens TW, et al. (1996) Serum immunoreactive-leptin concentrations in normal-weight and obese humans. N Engl J Med 334: 292-295.

23. Friedman JM (2009) Leptin at $14 \mathrm{y}$ of age: an ongoing story. Am J Clin Nutr 89: 973S-979S
24. Lee GH, Proenca R, Montez JM, Carroll KM, Darvishzadeh JG, et al. (1996) Abnormal splicing of the leptin receptor in diabetic mice. Nature 379: 632-635.

25. Bjørbaek C, Uotani S, da Silva B, Flier JS (1997) Divergent signaling capacities of the long and short isoforms of the leptin receptor. J Biol Chem 272: 32686-32695.

26. Bjørbaek C, Kahn BB (2004) Leptin signaling in the central nervous system and the periphery. Recent Prog Horm Res 59: 305-331.

27. Bjørbaek C, El-Haschimi K, Frantz JD, Flier JS (1999) The role of SOCS-3 in leptin signaling and leptin resistance. J Biol Chem 274: 30059-30065.

28. Zabolotny JM, Bence-Hanulec KK, Stricker-Krongrad A, Haj F, Wang Y, et al. (2002) PTP1B regulates leptin signal transduction in vivo. Dev Cell 2: 489-495.

29. Halaas JL, Gajiwala KS, Maffei M, Cohen SL, Chait BT, et al. (1995) Weight-reducing effects of the plasma protein encoded by the obese gene. Science 269: 543-546.

30. Pelleymounter MA, Cullen MJ, Baker MB, Hecht R, Winters D, et al. (1995) Effects of the obese gene product on body weight regulation in ob/ob mice. Science 269: 540-543.

31. Campfield LA, Smith FJ, Guisez Y, Devos R, Burn P (1995) Recombinant mouse $\mathrm{OB}$ protein: evidence for a peripheral signal linking adiposity and central neural networks. Science 269: 546-549.

32. Sandoval D, Cota D, Seeley RJ (2008) The integrative role of CNS fuelsensing mechanisms in energy balance and glucose regulation. Annu Rev Physiol 70: 513-535.

33. Field BC, Chaudhri OB, Bloom SR (2010) Bowels control brain: gut hormones and obesity. Nat Rev Endocrinol 6: 444-453.

34. Benoit SC, Clegg DJ, Seeley RJ, Woods SC (2004) Insulin and leptin as adiposity signals. Recent Prog Horm Res 59: 267-285.

35. Woods SC, D'Alessio DA (2008) Central control of body weight and appetite. J Clin Endocrinol Metab 93: S37-50.

36. Lin X, Taguchi A, Park S, Kushner JA, Li F, et al. (2004) Dysregulation of insulin receptor substrate 2 in beta cells and brain causes obesity and diabetes. J Clin Invest 114: 908-916.

37. Niswender KD, Morrison CD, Clegg DJ, Olson R, Baskin DG, et al. (2003) Insulin activation of phosphatidylinositol 3-kinase in the hypothalamic arcuate nucleus: a key mediator of insulin-induced anorexia. Diabetes 52: 227-231.

38. Myers MG Jr, Olson DP (2012) Central nervous system control of metabolism. Nature 491: 357-363.

39. Porte D Jr, Baskin DG, Schwartz MW (2005) Insulin signaling in the central nervous system: a critical role in metabolic homeostasis and disease from C. elegans to humans. Diabetes 54: 1264-1276.

40. Carvalheira JB, Siloto RM, Ignacchitti I, Brenelli SL, Carvalho CR, et al. (2001) Insulin modulates leptin-induced STAT3 activation in rat hypothalamus. FEBS Lett 500: 119-124.

41. Schwartz MW (2006) Central nervous system regulation of food intake. Obesity (Silver Spring) 14 Suppl 1: 1S-8S.

42. Heymsfield SB, Greenberg AS, Fujioka K, Dixon RM, Kushner R, et al. (1999) Recombinant leptin for weight loss in obese and lean adults: a randomized, controlled, dose-escalation trial. JAMA 282: 1568-1575.

43. Hukshorn CJ, Saris WH, Westerterp-Plantenga MS, Farid AR, Smith FJ, et al. (2000) Weekly subcutaneous pegylated recombinant native human leptin (PEG-OB) administration in obese men. J Clin Endocrinol Metab 85: 4003-4009.

44. El-Haschimi K, Pierroz DD, Hileman SM, Bjørbaek C, Flier JS (2000) Two defects contribute to hypothalamic leptin resistance in mice with diet-induced obesity. J Clin Invest 105: 1827-1832.

45. Prada PO, Zecchin HG, Gasparetti AL, Torsoni MA, Ueno M, et al. (2005) Western diet modulates insulin signaling, c-Jun $\mathrm{N}$-terminal kinase activity, and insulin receptor substrate-1ser307 phosphorylation in a tissue-specific fashion. Endocrinology 146: 1576-1587.

46. De Souza CT, Araujo EP, Bordin S, Ashimine R, Zollner RL, et al. (2005) Consumption of a fat-rich diet activates a proinflammatory response and 
induces insulin resistance in the hypothalamus. Endocrinology 146 4192-4199.

47. Thaler JP, Schwartz MW (2010) Minireview: Inflammation and obesity pathogenesis: the hypothalamus heats up. Endocrinology 151: 4109-4115.

48. Hotamisligil GS, Shargill NS, Spiegelman BM (1993) Adipose expression of tumor necrosis factor-alpha: direct role in obesity-linked insulin resistance. Science 259: 87-91.

49. Hotamisligil GS, Budavari A, Murray D, Spiegelman BM (1994) Reduced tyrosine kinase activity of the insulin receptor in obesity-diabetes. Central role of tumor necrosis factor-alpha. J Clin Invest 94: 1543-1549.

50. Schenk S, Saberi M, Olefsky JM (2008) Insulin sensitivity: modulation by nutrients and inflammation. J Clin Invest 118: 2992-3002.

51. Unger EK, Piper ML, Olofsson LE, Xu AW (2010) Functional role of cJun-N-terminal kinase in feeding regulation. Endocrinology 151: 671-682.

52. Zhang X, Zhang G, Zhang H, Karin M, Bai H, et al. (2008) Hypothalamic IKKbeta/NF-kappaB and ER stress link overnutrition to energy imbalance and obesity. Cell 135: 61-73.

53. Mori H, Hanada R, Hanada T, Aki D, Mashima R, et al. (2004) Socs3 deficiency in the brain elevates leptin sensitivity and confers resistance to diet-induced obesity. Nat Med 10: 739-743.

54. Howard JK, Flier JS (2006) Attenuation of leptin and insulin signaling by SOCS proteins. Trends Endocrinol Metab 17: 365-371.

55. Reed AS, Unger EK, Olofsson LE, Piper ML, Myers MG Jr, et al. (2010) Functional role of suppressor of cytokine signaling 3 upregulation in hypothalamic leptin resistance and long-term energy homeostasis. Diabetes 59: 894-906.

56. Bence KK, Delibegovic M, Xue B, Gorgun CZ, Hotamisligil GS, et al. (2006) Neuronal PTP1B regulates body weight, adiposity and leptin action. Nat Med 12: 917-924.

57. Picardi PK, Calegari VC, Prada PO, Moraes JC, Araújo E, et al. (2008) Reduction of hypothalamic protein tyrosine phosphatase improves insulin and leptin resistance in diet-induced obese rats. Endocrinology 149: 3870-3880

58. Münzberg H, Flier JS, Bjørbaek C (2004) Region-specific leptin resistance within the hypothalamus of diet-induced obese mice. Endocrinology 145: 4880-4889.

59. Zabolotny JM, Kim YB, Welsh LA, Kershaw EE, Neel BG, et al. (2008) Protein-tyrosine phosphatase $1 \mathrm{~B}$ expression is induced by inflammation in vivo. J Biol Chem 283: 14230-14241.

60. Benoit SC, Kemp CJ, Elias CF, Abplanalp W, Herman JP, et al. (2009) Palmitic acid mediates hypothalamic insulin resistance by altering PKCtheta subcellular localization in rodents. J Clin Invest 119: 2577-2589.

61. Thaler JP, Yi CX, Schur EA, Guyenet SJ, Hwang BH, et al. (2012) Obesity is associated with hypothalamic injury in rodents and humans. J Clin Invest 122: 153-162

62. Milanski M, Degasperi G, Coope A, Morari J, Denis R, et al. (2009) Saturated fatty acids produce an inflammatory response predominantly through the activation of TLR4 signaling in hypothalamus: implications for the pathogenesis of obesity. J Neurosci 29: 359-370.

63. Kleinridders A, Schenten D, Könner AC, Belgardt BF, Mauer J, et al. (2009) MyD88 signaling in the CNS is required for development of fatty acid-induced leptin resistance and diet-induced obesity. Cell Metab 10: 249-259.

64. Hotamisligil GS (2010) Endoplasmic reticulum stress and the inflammatory basis of metabolic disease. Cell 140: 900-917.

65. Ozcan L, Ergin AS, Lu A, Chung J, Sarkar S, et al. (2009) Endoplasmic reticulum stress plays a central role in development of leptin resistance. Cell Metab 9: 35-51.

66. Lehnardt S, Massillon L, Follett P, Jensen FE, Ratan R, et al. (2003) Activation of innate immunity in the CNS triggers neurodegeneration through a Toll-like receptor 4-dependent pathway. Proc Natl Acad Sci U S A 100: 8514-8519.

67. Belgardt BF, Brüning JC (2010) CNS leptin and insulin action in the control of energy homeostasis. Ann N Y Acad Sci 1212: 97-113.
68. Feng B, Yao PM, Li Y, Devlin CM, Zhang D, et al. (2003) The endoplasmic reticulum is the site of cholesterol-induced cytotoxicity in macrophages. Nat Cell Biol 5: 781-792.

69. Moraes JC, Coope A, Morari J, Cintra DE, Roman EA, et al. (2009) High fat diet induces apoptosis of hypothalamic neurons. PLoS One 4: e5045.

70. Pinto S, Roseberry AG, Liu H, Diano S, Shanabrough M, et al. (2004) Rapid rewiring of arcuate nucleus feeding circuits by leptin. Science 304: 110-115.

71. Horvath TL (2006) Synaptic plasticity in energy balance regulation. Obesity (Silver Spring) 14 Suppl 5: 228S-233S.

72. Horvath TL, Sarman B, García-Cáceres C, Enriori PJ, Sotonyi P, et al. (2010) Synaptic input organization of the melanocortin system predicts diet-induced hypothalamic reactive gliosis and obesity. Proc Natl Acad Sci U S A 107: 14875-14880.

73. Sousa-Ferreira L, Almeida LP de, Cavadas C (2013) Role of hypothalamic neurogenesis in feeding regulation. Trends Endocrinol Metab 25: 80-88.

74. Ramachandrappa S, Farooqi IS (2011) Genetic approaches to understanding human obesity. J Clin Invest 121: 2080-2086.

75. Coll AP, Farooqi IS, Challis BG, Yeo GS, O'Rahilly S (2004) Proopiomelanocortin and energy balance: insights from human and murine genetics. J Clin Endocrinol Metab 89: 2557-2562.

76. Stenlöf K, Wernstedt I, Fjällman T, Wallenius V, Wallenius K, et al. (2003) Interleukin-6 levels in the central nervous system are negatively correlated with fat mass in overweight/obese subjects. J Clin Endocrinol Metab 88: 4379-4383.

77. van de Sande-Lee S1, Pereira FR, Cintra DE, Fernandes PT, Cardoso AR et al. (2011) Partial reversibility of hypothalamic dysfunction and changes in brain activity after body mass reduction in obese subjects. Diabetes 60: 1699-1704.

78. Allen TL, Febbraio MA (2010) IL6 as a mediator of insulin resistance: fat or fiction? Diabetologia 53: 399-402.

79. Rotter V, Nagaev I, Smith U (2003) Interleukin-6 (IL-6) induces insulin resistance in 3T3-L1 adipocytes and is, like IL-8 and tumor necrosis factor-alpha, overexpressed in human fat cells from insulin-resistant subjects. J Biol Chem 278: 45777-45784.

80. Klover PJ, Zimmers TA, Koniaris LG, Mooney RA (2003) Chronic exposure to interleukin-6 causes hepatic insulin resistance in mice. Diabetes 52: 2784-2789.

81. Kim HJ, Higashimori T, Park SY, Choi H, Dong J, et al. (2004) Differential effects of interleukin-6 and -10 on skeletal muscle and liver insulin action in vivo. Diabetes 53: 1060-1067.

82. Klover PJ, Clementi AH, Mooney RA (2005) Interleukin-6 depletion selectively improves hepatic insulin action in obesity. Endocrinology 146: 3417-3427.

83. Wallenius V, Wallenius K, Ahrén B, Rudling M, Carlsten H, et al. (2002) Interleukin-6-deficient mice develop mature-onset obesity. Nat Med 8: 75-79.

84. Sadagurski M, Norquay L, Farhang J, D'Aquino K, Copps K, et al. (2010) Human IL6 enhances leptin action in mice. Diabetologia 53: 525-535.

85. Shirazi R, Palsdottir V, Collander J, Anesten F, Vogel H, et al. (2013) Glucagon-like peptide 1 receptor induced suppression of food intake, and body weight is mediated by central IL-1 and IL-6. Proc Natl Acad Sci U S A 110: 16199-16204.

86. Pedersen BK, Steensberg A, Fischer C, Keller C, Keller P, et al. (2004) The metabolic role of IL-6 produced during exercise: is IL-6 an exercise factor? Proc Nutr Soc 63: 263-267.

87. Flores MB, Fernandes MF, Ropelle ER, Faria MC, Ueno M, et al. (2006) Exercise improves insulin and leptin sensitivity in hypothalamus of Wistar rats. Diabetes 55: 2554-2561.

88. Ropelle ER, Flores MB, Cintra DE, Rocha GZ, Pauli JR, et al. (2010) IL-6 and IL-10 anti-inflammatory activity links exercise to hypothalamic insulin and leptin sensitivity through IKKbeta and ER stress inhibition. PLoS Biol 8. 
Citation: van de Sande-Lee S, Velloso LA (2014) Hypothalamic Alterations in Obesity. J Mol Genet Med S1: 026. doi: 10.4172/1747-0862.S1-026

Page 7 of 7

89. Bachis A, Colangelo AM, Vicini S, Doe PP, De Bernardi MA, et al. (2001) Interleukin-10 prevents glutamate-mediated cerebellar granule cell death by blocking caspase-3-like activity. J Neurosci 21: 3104-3112.

90. Gao JH (2001) Neuroimaging and obesity. Obes Res 9: 729-730.

91. Tataranni PA, DelParigi A (2003) Functional neuroimaging: a new generation of human brain studies in obesity research. Obes Rev 4: 229-238.

92. Carnell S, Gibson C, Benson L, Ochner CN, Geliebter A (2012) Neuroimaging and obesity: current knowledge and future directions. Obes Rev 13: 43-56.
93. Matsuda M, Liu Y, Mahankali S, Pu Y, Mahankali A, et al. (1999) Altered hypothalamic function in response to glucose ingestion in obese humans. Diabetes 48: 1801-1806.

94. Gautier JF, Chen K, Salbe AD, Bandy D, Pratley RE, et al. (2000) Differential brain responses to satiation in obese and lean men. Diabetes 49: 838-846.

95. Gautier JF, Del Parigi A, Chen K, Salbe AD, Bandy D, et al. (2001) Effect of satiation on brain activity in obese and lean women. Obes Res 9: 676-684.
This article was originally published in a special issue, entitled: "Molecular and Cellular Aspects in Obesity and Diabetes", Edited by Dr. Masayoshi

Yamaguchi, Emory University School of Medicine, USA 